\title{
General Assembly
}

Distr.: General

30 November 2015

Original: English

\section{Human Rights Council}

Thirty-first session

Agenda items 2 and 3

Annual report of the United Nations High Commissioner

for Human Rights and reports of the Office of the

High Commissioner and the Secretary-General

Promotion and protection of all human rights, civil political, economic, social and cultural rights, including the right to development

\section{Thematic study on the rights of persons with disabilities under article 11 of the Convention on the Rights of Persons with Disabilities, on situations of risk and humanitarian emergencies}

\section{Report of the Office of the United Nations High Commissioner for Human Rights}

Summary

In the present study, the Office of the United Nations High Commissioner for Human Rights sets out the standards on the human rights of persons with disabilities in situations of risk and humanitarian emergencies, and presents a harmonized understanding of existing international humanitarian law under article 11 of the Convention on the Rights of Persons with Disabilities. The aim of the study is to clarify the scope of the Convention in the context of ongoing global discussion relating to disasters and humanitarian emergencies, to identify good practices, and to make recommendations thereon. 


\section{Contents}

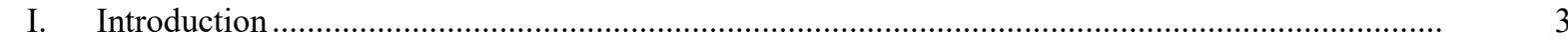

II Rights of persons with disabilities in situations of risk and humanitarian emergencies .................... 3

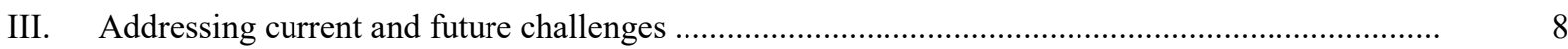

A. Key elements of humanitarian response effectiveness from a disability perspective ................ 9

B. Reducing the exclusion of persons with disabilities and managing risk .................................. 10

C. Serving the needs of persons with disabilities in situations of conflict...................................... 13

D. Transformation through innovation ..........................................................................................

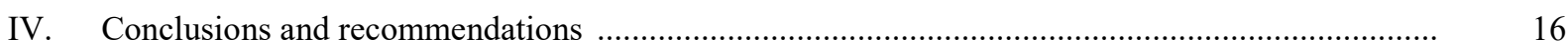




\section{Introduction}

1. In its resolution 28/4, the Human Rights Council requested the Office of the United Nations High Commissioner for Human Rights (OHCHR) to prepare a report on the rights of persons with disabilities under article 11 of the Convention on the Rights of Persons with Disabilities, on situations of risk and humanitarian emergencies, in consultation with States parties and other relevant stakeholders, regional organizations, the Special Rapporteur on the rights of persons with disabilities, civil society organizations, including organizations of persons with disabilities, and national human rights institutions. The Council also requested that contributions be submitted in an accessible format and be made available together with the report in an easy-to-read-version on the OHCHR website prior to the thirty-first session of the Council.

2. Pursuant to the request of the Human Rights Council, OHCHR solicited contributions and received 27 responses from States parties, seven from national human rights institutions and 11 from civil society organizations and other stakeholders. ${ }^{1}$

\section{Rights of persons with disabilities in situations of risk and humanitarian emergencies}

3. The Convention on the Rights of Persons with Disabilities has marked a paradigm shift, adopting a human rights-based approach to disability with a focus on the removal of barriers to the inclusion and participation of persons with disabilities in society and on the enjoyment of their rights on an equal basis with others. International humanitarian law on the other hand has been codified under previously dominant understandings of disability, notably the medical model of disability, which focuses exclusively on the impairment of the person and reflects a paternalistic approach to persons with disabilities. ${ }^{2}$ These concepts have been superseded by the human rights-based approach to disability framed in the Convention.

4. Article 11 of the Convention on the Rights of Persons with Disabilities reinforces and specifies States' obligations under international humanitarian law to ensure the protection and safety of persons with disabilities in situations of risk, including armed conflict, humanitarian emergencies and natural disasters, consistent with the approach adopted by the Convention. Notably, during the negotiations on the Convention, the need to embrace a human rights-based approach to disability in the humanitarian protection of persons with disabilities led to the discarding of references to persons with disabilities as a "vulnerable" or "neglected" group in connection with emergency situations. The Geneva Conventions use terms such as "wounded" and "sick", which, when used without further qualifications to refer to persons with disabilities, contradict the standards of the Convention on the Rights of Persons with Disabilities. Article 11 of the Convention calls for international humanitarian law to be read through a human rights-based approach to disability. This will necessarily lead to substantive changes in policy and practice.

5. The Committee on the Rights of Persons with Disabilities has developed several standards in its concluding observations under article 11. States are required to adopt or

\footnotetext{
1 The full texts of submissions received are available on the OHCHR website at www.ohchr.org/EN/Issues/Disability/Pages/StudiesReportsPapers.aspx.

2 See for example the Geneva Conventions of 12 August 1949 and the Protocols additional to the Geneva Conventions of 1977.
} 
reform national emergency response plans and protocols, making them inclusive of, and accessible to, persons with disabilities in their design and implementation. ${ }^{3}$ These reforms should include persons with disabilities in evacuation plans ${ }^{4}$ and ensure the necessary budget allocations. ${ }^{5}$ Importantly, States parties are required to mainstream disability in their migration and refugee policies ${ }^{6}$ and in all humanitarian aid channels. ${ }^{7}$ Furthermore, the Committee has underscored the duty of States to ensure the participation of organizations of persons with disabilities in these measures, with due consideration accorded to their input and recommendations, including in setting priorities for aid distribution. ${ }^{8}$

6. The Committee has urged that the safety of all children with disabilities in conflictaffected areas be ensured and prioritized, in particular of those living in institutions. ${ }^{9}$ It has also urged the systematic registration of internally displaced persons with disabilities, ${ }^{10}$ and called for their situation as well as of those in refugee camps to be monitored, with the purpose of ensuring an adequate standard of living. ${ }^{11}$ In addition, it has stated that the administrative detention of persons with disabilities in migration and asylum-seeking contexts is not consistent with the Convention when it is applied without the provision of adequate support and reasonable accommodation. ${ }^{12}$

7. The Committee has highlighted the duty to ensure that all emergency-related information be made available in formats accessible to persons with different types of impairments, ${ }^{13}$ including to deaf persons through sign language, and in the various languages spoken in its territory, including those used by indigenous peoples. ${ }^{14}$ It has also required disability-awareness training for all civil defence staff, rescue and emergency personnel, and for all potential actors involved in humanitarian emergencies. ${ }^{15}$

8. In its statement following the earthquake and the subsequent tsunami that struck Chile on 27 February 2010, the Committee identified some of the additional barriers that contributed to the disproportionate adverse impact of humanitarian emergencies on persons with disabilities. In its statement on disability inclusion in the Third World Conference on Disaster Risk Reduction and Beyond, the Committee called upon all States parties, the United Nations and all agencies in the United Nations system and the international community to, inter alia, ensure disability inclusion in the final outcome of the Conference leading to true disability-inclusive disaster risk reduction. The Sendai Framework for Disaster Risk Reduction 2015-2030 adopted at the Conference, ${ }^{16}$ contained important

3 See for example CRPD/C/PRY/CO/1, para. 28;CRPD/C/AZE/CO/1, para. 25; CRPD/C/KOR/CO/1, para. 20; CRPD/C/DEU/CO/1, para. 24;CRPD/C/UKR/CO/1, para. 23;CRPD/C/QAT/CO/1, para. 22; $\mathrm{CRPD} / \mathrm{C} / \mathrm{KEN} / \mathrm{CO} / 1$, para. 22 (a);CRPD/C/AUS/CO/1, para. 23; and CRPD/C/CZE/CO/1, para. 21.

4 See CRPD/C/UKR/CO/1, para. 23.

5 See CRPD/C/COK/CO/1, para. 22.

See CRPD/C/EU/CO/1, para. 35 .

7 See CRPD/C/UKR/CO/1, para. 23.

$8 \mathrm{See} \mathrm{CRPD} / \mathrm{C} / \mathrm{UKR} / \mathrm{CO} / 1$, para. 23.

9 Ibid., para. 14.

Ibid., para. 25

See $\mathrm{CRPD} / \mathrm{C} / \mathrm{KEN} / \mathrm{CO} / 1$, para. 22 (c).

$12 \mathrm{See}$ CRPD/C/EU/CO/1, paras. 34-35.

13 See CRPD/C/SLV/CO/1, para. 26; CRPD/C/DEN/CO/1, para. 31; CRPD/C/MEX/CO/1, para 22(b); $\mathrm{CRPD} / \mathrm{C} / \mathrm{GAB} / \mathrm{CO} / 1$, para. 27.

14 See CRPD/C/TKM/CO/1, para. 24;CRPD/C/MNG/CO/1, para. 20;CRPD/C/DEU/CO/1, para. 24 $\mathrm{CRPD} / \mathrm{C} / \mathrm{DOM} / \mathrm{CO} / 1$, para. 19; $\mathrm{CRPD} / \mathrm{C} / \mathrm{COK} / \mathrm{CO} / 1$, para. 22; $\mathrm{CRPD} / \mathrm{C} / \mathrm{MEX} / \mathrm{CO} / 1$, para. 22 (a); and $\mathrm{CRPD} / \mathrm{C} / \mathrm{KEN} / \mathrm{CO} / 1$, para. 22 (b)

15 See CRPD/C/AZE/CO/1, para. 25; CRPD/C/MEX/CO/1, para. 22(c); and CRPD/C/DEN/CO/1, para. 31.

16 See A/CONF.224/6, chap. I. 
provisions in that direction. Lastly, the statement on disability inclusion at the World Humanitarian Summit adopted by the Committee at its fourteenth session contained a number of key related recommendations.

9. Compliance with article 11 of the Convention on the Rights of Persons with Disabilities requires observation of its other provisions. Article 5, on equality and nondiscrimination, is crucial in informing inclusive policies on emergency situations, including through the provision of reasonable accommodation. States parties must ensure close consultation with, and the active involvement of, organizations of persons with disabilities in the development, implementation and monitoring of emergency-related legislation and policies (art. 4.3). This could necessitate non-conditional public funding for the independent, full and effective participation of civil society. ${ }^{17}$ States' duties under article 9, on accessibility, are indispensable to ensure that persons with disabilities are not excluded during situations of risk and humanitarian emergency, especially regarding information and alert mechanisms (see paras. 5 and 7 above). They are also crucial in upholding and promoting universal design (art. 2), particularly during reconstruction. ${ }^{18}$

10. Article 12 of the Convention, on the right to equal recognition before the law, upholds the exercise of legal capacity by adults with disabilities and requires the implementation of supported decision-making, moving away from substituted decisionmaking schemes. ${ }^{19}$ This right is particularly important in situations of emergency, when persons with disabilities are required to make key decisions, including on their property, living arrangements, finance (including financial support) and emergency medical treatments. This right cannot be subjected to any derogation, including in emergency situations. ${ }^{20}$ Article 14 establishes a non-discriminatory approach to the deprivation of liberty. This includes an absolute ban on the deprivation of liberty based on impairments or on discriminatory practices in places of detention, such as the use of separate facilities and the denial of reasonable accommodation.

11. The provision of health and rehabilitation services, especially support for psychosocial recovery, must be compliant with articles 25 and 26 of the Convention. Notably, respect for autonomy, including the right to community-based services and free and informed consent, should inform good practice. Health facilities should guarantee support for those in need of such support in decision-making. Medical personnel should respect the right of every person to accept or refuse medical treatment, including mental health treatment. In addition, it is important to highlight that prevention of primary impairments should not be included in disability policies, and that such exclusion should not undermine budgets associated with the protection of persons with disabilities. ${ }^{21}$

12. According to article 19 (c) of the Convention, services and facilities during emergency situations and reconstruction processes must be inclusive of and available to persons with disabilities, and responsive to their needs. In article 28, States recognize the right of persons with disabilities to an adequate standard of living, on an equal basis with others. This article should be applied to safeguard access by persons with disabilities to humanitarian assistance and aid and to post-emergency social protection schemes, including poverty reduction programmes that take into account disability-related expenses and needs. Reparations for breaches of international humanitarian law and human rights law should

17 See CRPD/C/HRV/CO/1, para. 53.

18 See CRPD/C/GC/2, para. 36 .

19 See CRPD/C/GC/1.

${ }^{20}$ Ibid., para. 5.

21 Without prejudice to article 12 of the International Covenant on Economic, Social and Cultural Rights. 
not be confused with social protection schemes, as they have different bases and purposes. If reparations apply, they should be considered independently and in addition to social protection schemes.

13. Article 32 (1)(a) states that international cooperation, which might be an important source of resources in emergency situations, ${ }^{22}$ should be inclusive of and accessible to persons with disabilities and be, in all cases, respectful of the standards set out in the Convention. Among other Convention-based obligations, the implementation of article 32 (1)(a) requires humanitarian actors, when using international cooperation funds, to comply with accessibility, provide reasonable accommodation and ensure the participation of persons with disabilities in decision-making, in order to prevent, for example, persons with disabilities who face inaccessibility from returning to conflict areas owing to a lack of effective options.

14. The Convention on the Rights of Persons with Disabilities applies throughout the continuum of humanitarian emergencies, whether in situations of conflict, foreign occupation or natural disaster. Exceptionally, article 4 of the International Covenant on Civil and Political Rights allows a State to derogate temporarily from a part of its obligations under the Covenant during a legally declared state of emergency. ${ }^{23}$ This is possible only in specifically designated circumstances, and under strict substantive and procedural requirements, always in compliance with the State's obligations under international humanitarian and human rights law, without discrimination and only "to the extent strictly required by the exigencies of the situation" Importantly, it also establishes that, for certain rights, there can be no derogation in any circumstance (see para. 12 above) with regard to equal recognition before the law.

15. The Convention applies to all persons with disabilities, regardless of their legal status or nationality. This approach is consistent with the recommendation of the Maastricht Principles on Extraterritorial Obligations of States in the Area of Economic, Social and Cultural Rights, which clarify the human rights obligations of States beyond their own borders, especially their obligation to avoid causing harm and to protect human rights extraterritorially (principles I(4) and II(8) and (13)). Several treaty bodies have endorsed the extraterritorial application of human rights treaties. The Committee on the Elimination of Discrimination against Women, in its general recommendation No. 30, stated that States parties are at all times responsible for all their actions affecting the human rights of persons who are in territories under their effective control. ${ }^{24}$ The Human Rights Committee and the Committee on the Elimination of Racial Discrimination have also endorsed this criterion in their concluding observations. ${ }^{25}$ Lastly, the International Court of Justice has supported the applicability of human rights instruments outside the national territory. ${ }^{26}$

16. The Committee on the Rights of the Child, in its general comment No. 9, stated that States parties must ensure access to adequate health and social services, including psychosocial recovery and social reintegration, to children with disabilities affected by an armed conflict. ${ }^{27}$ It has also recommended that, in a post-conflict context, resources for education be increased to build and reconstruct adequate school facilities and that inclusive

22 See CRPD/C/COK/CO/1, para. 22,

23 See CCPR/C/21/Rev.1/Add.11.

24 See also CEDAW/C/ISR/CO/5, paras. 12-13.

25 See CCPR/C/ISR/CO/3, para. 5; CERD/C/GBR/CO/18-20, para. 12; and CERD/C/ISR/CO/14-16, paras. 20, 27 and 29.

26 See advisory opinion of the International Court of Justice on the Legal Consequences of the Construction of a Wall in the Occupied Palestinian Territory of 9 July 2004, paras. 106-113.

$27 \mathrm{CRC} / \mathrm{C} / \mathrm{GC} / 9$, para. 55. 
educational systems be created, including for children with disabilities. ${ }^{28}$ The Committee on the Elimination of Discrimination against Women, in a statement on the situation of women in Gaza, in July 2014, expressed concern at the number of women and girls, including those with disabilities, facing forced displacement, with little or no access to social services, and at women with disabilities either left behind in camps or in reconstruction contexts who were subjected to gender-based and sexual violence. ${ }^{29}$ It has requested States to pay particular attention to the needs of internally displaced women, including women with disabilities. $^{30}$

17. In its conclusion No. 110 (LXI) of 12 October 2010, the Office of the United Nations High Commissioner for Refugees (UNHCR) recalled the Convention on the Rights of Persons with Disabilities to underscore the principles of dignity and equality, nondiscrimination, and respect for the rights and participation of refugees and others with disabilities protected and assisted by UNHCR. It encourages States parties to ensure adequate protection for refugee women and children with disabilities and to facilitate access to mainstream and specialized services, including those provided through international cooperation. Furthermore, according to the principles on housing and property restitution for refugees and displaced persons, ${ }^{31}$ persons with disabilities are entitled to have restored to them any housing, land and/or property of which they were arbitrarily deprived, or failing that, to be compensated.

18. Recent developments show an increasing awareness of persons with disabilities in emergency situations. The African Union Convention for the Protection and Assistance of Internally Displaced Persons in Africa (Kampala Convention) requires States parties to respect and protect the human rights of internally displaced persons, including the rights to non-discrimination, equality and equal protection of the law (art. 1 (d)) and, in particular, to provide persons with disabilities with special protection and assistance (art. 9.2 (c)). In its resolution $\mathrm{CD} / 13 / \mathrm{R} 9$ on the inclusion of persons with disabilities, the Council of Delegates of the International Red Cross and Red Crescent Movement, recalling the Convention on the Rights of Persons with Disabilities, urged all components of the Movement to work with Governments to help to implement relevant instruments of international law to support the rights of persons with disabilities, and to address discrimination, change perceptions and combat stereotypes and prejudice.

19. In June 2014, States parties to the Convention on the Prohibition of the Use, Stockpiling, Production and Transfer of Anti-Personnel Mines and on Their Destruction adopted the Maputo Action Plan 2014-2019, under which they committed to integrate those with disabilities into the broader legal frameworks related to the rights of persons with disabilities, reflecting thus a more updated understanding of the issue. The preamble to the Convention on Cluster Munitions refers directly to the importance of the Convention on the Rights of Persons with Disabilities, recognizing the principle of non-discrimination against and among persons with disabilities. The Convention also requires States parties to develop and implement plans and budgets for including persons with disabilities considered in the treaty in existing national disability, development and human-rights frameworks and mechanisms (art. 5.2 (c) and (e)). The Dubrovnik Action Plan reinforces this obligation. These two treaties specifically regard as protected groups those who acquired their impairment through the explosion of land mines and cluster munitions. The obligations stemming from the treaties on monitoring the situation of these particular groups should not

\footnotetext{
${ }^{28} \mathrm{CRC} / \mathrm{C} / \mathrm{AFG} / \mathrm{CO} / 1$, para. 61 (a).

29 See CEDAW/C/UGA/CO/7, para. 25.

30 See CEDAW/C/NGA/CO/6, para. 38; and CEDAW/C/RWA/CO/6, para. 39.

31 E/CN.4/Sub.2/2005/17, annex.
} 
lead to unequal treatment among persons with disabilities. The cause of impairment is irrelevant to the protection of the human rights of persons with disabilities.

20. The Sendai Framework for Disaster Risk Reduction 2015-2030 (see para. 8 above) is a good reference, reflecting a human rights-based sustainable development agenda inclusive of and accessible to persons with disabilities. According to the Framework, persons with disabilities and their organizations have a critical role to play at all stages of disaster risk reduction planning (para. 36 (a)(iii)). It also requires all disaster risk reduction policies to integrate a disability perspective (III (19)(d)) and inclusive risk-informed decision-making based on the dissemination of information disaggregated by, among other factors, disability (III (19)(g)).

\section{Addressing current and future challenges}

21. Reliable data on the number of persons with disabilities facing conflict situations and natural disasters are scarce. The World Health Organization (WHO) estimates that 15 per cent of the world's population have impairments. ${ }^{32}$ UNHCR estimates that there are 59.5 million people forcibly displaced, worldwide. ${ }^{33}$ Based upon these estimates, approximately 7.65 million persons with disabilities would face forced displacement. ${ }^{34} \mathrm{~A}$ survey specific to refugees shows that the prevalence of refugees with disabilities is in fact higher ${ }^{35}$ consequently, these figures may actually underestimate the dimensions of the problem.

22. Emergencies disproportionally affect persons with disabilities; for example, data from Japan confirm that persons with disabilities are four times more likely to die when a disaster strikes. ${ }^{36}$ Persons with disabilities are often exposed to a higher rate of abuse, neglect and abandonment in situations of risk, armed conflict and humanitarian emergency. Moreover, programme assistance, adequate shelter, communication and means of transportation tend to be inaccessible, resulting in widespread violations of their human rights. ${ }^{37}$ Older persons, women, boys and girls with disabilities are at particular risk of discrimination, exploitation, violence (including sexual and gender-based violence) and exclusion from support and services in the context of a crisis. ${ }^{38}$

23. In the present study, OHCHR addresses four themes relevant to ongoing global debates on disasters and humanitarian emergencies (largely corresponding to the four major themes of the thematic consultations conducted at the World Humanitarian Summit), with the aim of making relevant recommendations. Participation by organizations of persons with disabilities is essential for the design, implementation, evaluation and review of policies, including in the global debate (see paras. 5, 9 and 13 above). Accountability

32 WHO and the World Bank, World Report on Disability, 2011, p. 29.

33 UNCHR, World at War: Global Trends. Forced Displacement in 2014, p. 8.

34 Women's Refugee Commission, Disability Inclusion: Translating Policy into Practice in Humanitarian Action, March 2014, p. 1

35 The survey estimated that as many as 22 per cent of Syrian refugees surveyed had an impairment. See HelpAge International and Handicap International, Hidden victims of the Syrian crisis: disabled, injured and older refugees, 2014, p. 6.

36 See the Statement of Voluntary Commitments of Organizations Working on Disability-Inclusion for the 6th Asian Ministerial Conference for Disaster Risk Reduction, Bangkok, 22-26 June 2014.

37 See "Addressing the vulnerability and exclusion of persons with disabilities: the situation of women and girls, children's right to education, disasters and humanitarian crises" (CRPD/CSP/2015/4), para. 21.

38 See UNHCR, conclusion No. 110 (LXI) on refugees with disabilities and other persons with disabilities protected and assisted by UNHCR, 12 October 2010. 
mechanisms should give primary consideration to the affected population, ${ }^{39}$ including to persons with disabilities and their representative organizations. Spain, for example, has legislation (Ley 17/2015, arts. 3 (2) and 7) recognizing the right to participation in humanitarian contexts. Equality and non-discrimination based on disability must inform all legislation, policies and procedures, including the provision of reasonable accommodation. The empowerment of persons with disabilities through, inter alia, awareness-raising, partnerships, capacity-building and the adequate allocation of resources is vital to enable their meaningful participation and to prevent violations of their rights. Lastly, law, policy and practice should be in line with the Convention on the Rights of Persons with Disabilities and other human rights standards (see paras. 5-13 above).

\section{A. Key elements of humanitarian response effectiveness from a disability perspective}

24. In order to improve humanitarian response effectiveness with regard to persons with disabilities, it is crucial to foster collaboration between local, national and international organizations working on disability. To that end, ensuring a substantive dialogue and the dissemination of good practices among persons with disabilities and their representative organizations on the one hand, and those working on risk and humanitarian emergencies on the other, is imperative. Such practices serve to raise awareness of the human rights of persons with disabilities and of their relevance in strengthening the implementation of humanitarian emergency assistance. ${ }^{40}$

25. Data and coherent global indicators, as well as analysis of existing information, on persons with disabilities are generally lacking, even though they are an important element in the design of inclusive policies on humanitarian emergencies, as required by article 31 of the Convention on the Rights of Persons with Disabilities. Consequently, there is a need to strengthen the collection, management, disaggregation and analysis of information on persons with disabilities in order to foster inclusion and to address discrimination on the basis of disability, not to mention multiple and intersectional forms of discrimination. The existing frameworks established by the Security Council for the protection of civilians, women, girls and boys in conflict provide a platform that could be extended to include persons with disabilities. This mainstreaming process would provide the necessary data collection mechanisms at a low cost for humanitarian actors. The Council set a precedent in this direction when it decided, in its resolution 2217 (2015), that the mandate of the United Nations Multidimensional Integrated Stabilization Mission in the Central African Republic would include the priority tasks of, inter alia, monitoring, helping to investigate and reporting on violations and abuses committed against children, women and persons with disabilities, which led to the latter group's inclusion in data collection efforts.

26. It is equally important that persons with disabilities be identified in situations of risk and during the recovery phase. Lack of systematic identification can lead to the exclusion of persons with disabilities from programme assistance and resources, including water, shelter and clothing. When contingency plans are being designed, the ability to map the location of the target population and to compile information on their support needs can help to address them better. ${ }^{41}$ In Mexico, the National Centre on Prevention of Disasters

39 See "The Centrality of Protection in Humanitarian Action", statement by the Inter-Agency Standing Committee, p. 2.

40 UNHCR, conclusion No. 110 (LXI) (see footnote 38), paras. (b), (d) and (e).

41 BC Coalition of People with Disabilities, A Road Map to Emergency Planning for People with Disabilities (available from www.disabilityalliancebc.org/docs/emergpreproadmap.pdf), p. iii. See 
identifies the domicile of persons with disabilities to prioritize their transportation in the event of an emergency. Collecting information through comprehensive needs assessments that disaggregate data by age, sex and impairment can facilitate risk management, planning and the implementation of risk reduction strategies. ${ }^{42}$ Furthermore, humanitarian actors, Governments and civil society organizations would greatly benefit from sharing data and information to better protect the rights of persons with disabilities. Several States, including Chile, Egypt, Fiji, Indonesia and Lebanon, have undertaken to reform their census and national or local surveys to collect disaggregated data on persons with disabilities.

27. More applied qualitative research should be generated to achieve a comprehensive understanding of the issues related to persons with disabilities in humanitarian emergencies. Such research should favour the use of participatory methodologies in order to better depict the requirements, experiences and priorities of persons with disabilities and to promote the development of inclusive policies and practices. In this regard, some efforts have been made by States parties jointly with academia and international organizations. Australia, through the University of Sydney, has supported initiatives to strengthen collaboration between UNCHR, the International Committee of the Red Cross (ICRC) Special Fund for the Disabled and the Women's Refugee Commission to address the rights of persons with disabilities in humanitarian emergencies. ${ }^{43}$ Similarly, Finland supports a collaborative project between UNCHR and the Women's Refugee Commission that involves consultation with displaced persons with disabilities to identify and address protection concerns. ${ }^{44}$

\section{B. Reducing the exclusion of persons with disabilities and managing risk}

28. Information must be provided in accessible formats before, during and after a risk situation (see para. 7 above). This is crucial to ensure the safety of persons with disabilities, especially of those with hearing, visual and intellectual impairments. Furthermore, information should be provided in the relevant languages, including those used by asylum seekers. In Spain, publicly-funded researchers have developed the means to ensure the accessibility of emergency notification systems. ${ }^{45}$ Chile too funds projects aimed at making emergency-related information accessible.

29. Evacuation systems must be improved. Persons with disabilities are more likely to be overlooked by evacuation strategies in emergencies. A recent United Nations survey of more than 5,000 people with disabilities from 126 countries found that only 20 per cent could evacuate immediately and without difficulty in the event of a sudden hazard, while the remainder reported that they could evacuate with some degree of difficulty. ${ }^{46}$ Evacuation strategies should give specific attention to the requirements of persons with

also National Fire Protection Association, Emergency Evacuation Planning Guide for People with Disabilities, June 2007, p. 8.

42 See WHO, Guidance Note on Disability and Emergency Risk Management for Health, 2013, pp. 20 25; Women's Refugee Commission, Disability Inclusion (see footnote 34), pp. 17, 18 and 29; and UNICEF, Children and Young People with Disabilities, Fact Sheet, May 2013, p. 10.

43 The Government of Australia has also funded a collaborative project between the University of Sydney and the Arbeiter-Samariter-Bund that includes consultation with persons with disabilities. See http://sydney.edu.au/health-sciences/cdrp/projects/pipddmi.shtml.

44 See Ministry for Foreign Affairs of Finland, UNHCR/Strengthening protection of persons with disabilities in forced displacement, 19 September 2014.

45 A. Malizia et al, "SEMA4A: An ontology for emergency notification systems accessibility", Expert Systems with Applications, vol. 37, No. 4 (April 2010), pp. 3380-3391.

46 United Nations Office for Disaster Risk Reduction, "UN global survey explains why so many people living with disabilities die in disasters", press release, 10 October 2013. 
disabilities, including to those residing in institutions. States must ensure that persons with disabilities are able to take their assistive devices and equipment with them or, if impossible, to replace them. Attention should be given to the maintenance, repair and necessary update of assistive devices, as well as the support necessary for their effective use, particularly in rural areas and camps. ${ }^{47}$ Evacuations are particularly challenging for those with significant support requirements. It is important to ensure that adequate support is in place and available.

30. A lack of accessible information and support can prevent persons with disabilities from having access to humanitarian aid, including shelter, food and non-food items, medical assistance and family tracing. For example, persons with physical impairments are prevented from reaching collection points, which thus exposes them to substantive deprivation of basic services and goods and to the risk of exploitation owing to a reliance on others for assistance.

31. Water and sanitation facilities in emergency and temporary shelters should be accessible to those with disabilities. Priority should be given to transitional shelter, which should be close to a water supply and sanitary facilities. It is important that shelter managers consult with persons with disabilities and their families to better adapt these facilities and, failing adequate solutions, on how to prioritize relocation.

32. Health and rehabilitation services should be made available in an accessible and culturally adequate fashion for persons with disabilities. Access to medical intervention, regular medication and treatment of chronic illnesses should be granted on an equal basis with others, including the provision of reproductive health services for women and girls with disabilities. Support should be provided to enable people to better cope with stress, anxiety and pre-existing conditions, given that mental health issues may also be triggered by situations of risk. In Colombia, for example, the Ministry of Social Protection outlines in an emergency guide on mental health dedicated procedures to deliver mental health services to different groups in emergency situations, including persons with disabilities, and advice for professionals on the use of sign language, Braille, large print and other means and modes of communication. ${ }^{48}$

33. Ultimately, effective interventions largely depend on the availability of funds. Adequate, timely and predictable resources should be in place to give effect to commitments for inclusive emergency preparedness and response. It is essential for donors to invest in humanitarian efforts that are inclusive of persons with disabilities. States should refrain from causing harm in their international cooperation efforts by promoting practices contrary to the Convention on the Rights of Persons with Disabilities. Instead, they should consider using a human rights-based approach in the emergency management cycle.

34. Risk situations may render persons with disabilities more vulnerable to violence, neglect, physical abuse or sexual exploitation, while also weakening law enforcement and fracturing support and safety mechanisms. Those at greatest risk are women, girls and boys and individuals who live alone or in isolation. It is important that potential risks be identified and adequate assistance be in place, including legal aid, in order to ensure that persons with disabilities have access to protection and community-based support services.

35. Child protection mechanisms should be age- and gender-appropriate. Relevant information should be available in suitable formats for boys and girls, and suited to different types of impairments. Medical, legal, psychological, social, educational and other

47 UNHCR, Working with Persons with Disabilities in Forced Displacement, 2011, p. 8.

48 Ministerio de la Protección Social, Guía de Atención en Salud Mental en Emergencias y Desastres, Bogotá, June 2011. 
services addressing victims of sexual violence must be accessible to boys, girls and adolescents with disabilities. Education has an important role in supporting boys, girls and adolescents with disabilities as they transition into the recovery phase of conflict or disaster. Access to inclusive education strengthens community-based links and can reduce insecurity in camps and temporary shelters. ${ }^{49}$

36. Humanitarian emergencies create and trigger infrastructural barriers to services, including destroyed bridges, roads and buildings. The provision of mobile services, home visits and accessible transport can help to overcome infrastructural barriers during humanitarian emergencies. The implementation of mobile services is in no case, however, a substitute for the general obligation of States parties to render facilities and services available to the general public accessible to and inclusive of persons with disabilities.

37. Worldwide, persons with disabilities are overrepresented among the poor and are among the most excluded. ${ }^{50}$ The Sustainable Development Goals and the ensuing development policies must address these needs in a targeted way, highlighting the need for sustainable livelihoods for persons with disabilities living in poverty and those affected by protracted crisis. Food, water and nutritional security should be priority issues. A multidimensional approach to sustainable development should be adopted; one that encourages accountability to affected populations and helps them to build livelihoods that are more resilient to disaster and conflict. ${ }^{51}$ Building resilience, strengthening access to inclusive quality education and decent work, and reducing inequalities within and among countries (including gender-based inequalities) can better prepare States to face emergencies. ${ }^{52}$

38. The realization of the right to development increases the resilience of communities and supports the implementation of the Convention on the Rights of Persons with Disabilities for all persons with disabilities. Positive measures introduced through law and policies to foster inclusion in the labour market - such as employment quotas in both the private and public sectors, and the promotion of self-employment - are essential to allow persons with disabilities to be better prepared and equipped for emergency situations.

39. States should take measures to ensure that persons with disabilities have adequate support to rebuild their lives and livelihoods in post-disaster and post-conflict situations. Temporary and permanent employment opportunities should be provided, together with vocational training. Public subsidies can enable employers to hire persons with disabilities by meeting the cost of modifying the workplace or acquiring additional equipment, as well as providing for reasonable accommodation, if required.$^{53}$ Persons with disabilities should take an active part in community reactivation, as their exclusion affects their own lives as well as of the entire community. ${ }^{54}$

49 UNHCR, Working with Persons with Disabilities (see footnote 47), p. 12.

50 See WHO and the World Bank, World Report on Disability (see footnote 32), pp. 10-13.

51 Office for the Coordination of Humanitarian Affairs, "Humanitarian concerns in the post-2015 development agenda", Position paper and key messages, 2013, p. 2.

52 See General Assembly resolution 69/315, paras. 23 and 25 and Goals 4.5, 8.5, 11.2 and 11.7.

53 See OHCHR, From Exclusion to Equality: Realizing the Rights of Persons with Disabilities, 2007, pp. 85-88.

54 It is estimated that exclusion of persons with disabilities entails losses between 3 and 7 per cent of GDP; see S. Buckup, "The price of exclusion: the economic consequences of excluding people with disabilities from the world of work", Employment Working Paper No. 43, Geneva, International Labour Organization (ILO), 14 December 2009. 


\section{Serving the needs of persons with disabilities in situations of conflict}

40. The Committee on the Rights of Persons with Disabilities, in its statement on disability inclusion (see para. 8 above), recognized the increased exposure to risk of persons with disabilities during conflict and foreign occupation, particularly in its gender dimension. The Convention on the Rights of Persons with Disabilities was built upon the basis that peace and security in observance of applicable human rights instruments are indispensable for the full protection of persons with disabilities in these contexts. In its resolution 9/9, the Human Rights Council reiterated that effective measures to guarantee and monitor the implementation of human rights should be taken in respect of civilian populations in situations of armed conflict, including people under foreign occupation. The provisions of the Convention, indivisible and interdependent, should be read in the light of these considerations.

41. In its resolution 1894 (2009), the Security Council highlighted the particular impact that armed conflicts have on persons with disabilities. More recently, in its resolutions 2217 (2015) and 2225 (2015), the Council expressed concern over the situation of persons with disabilities, including abandonment, violence and lack of access to basic services, and emphasized the need for humanitarian responses to include persons with disabilities, especially children. Indeed, persons with disabilities should have access to protection and to their basic requirements on an equal basis with other civilians during situations of armed conflict. The President of the Security Council, in a statement delivered on 12 February 2014 during consideration by the Council of the item entitled "Protection of civilians in armed conflict", reaffirmed that parties to armed conflict bear the fundamental responsibility of taking all feasible steps to ensure the protection of affected civilians, and to meet their basic needs, including the specific needs of persons with disabilities. ${ }^{55}$ Highlevel support and internationally agreed standards and guidelines on inclusion of persons with disabilities in humanitarian action are essential to fulfil their rights in these contexts.

42. Parties to armed conflicts have an obligation to give effective advance warning prior to an attack that may affect the civilian population. ${ }^{56}$ This obligation may be achieved by different means of communication, including audio, written, visual and alternative means, while respecting diversity. Failure to comply with this obligation in an accessible and inclusive manner amounts to discrimination on the basis of disability.

43. Evidence has shown that, during conflict, the families of persons with disabilities without adequate support often have to choose between risking their own lives while trying to save a relative with disability or leaving the said relative behind. ${ }^{57}$ States, non-State actors, transitional Governments and non-governmental aid agencies should take into account persons with disabilities in their response to crisis and recovery actions to ensure their safety. Some States have established specific mechanisms to guarantee access to aid for persons with disabilities; for example, during the conflict in Lebanon in 1996, the authorities were able to locate and distribute aid to persons with disabilities by means of a national voluntary identification system.

44. Despite the principles of special protection and rules laid down under international law that forbid the participation of children in armed conflict, thousands of children still

55 S/PRST/2014/3.

56 Protocol Additional to the Geneva Conventions of 12 August 1949 and relating to the Protection of Victims of International Armed Conflicts (Protocol I), art. 57 (2)(c).

57 Human Rights Watch, "Central African Republic: People With Disabilities Left Behind”, 28 April 2015. 
take an active part in hostilities and are themselves victims of such events. ${ }^{58}$ Additionally, there is increased concern about the use of children with disabilities as suicide bombers. ${ }^{59}$ States parties must review their national criminal legislation to ensure prosecution and punishment for grave breaches of international humanitarian law. ${ }^{60}$ They should also collect data, including disaggregated data, regarding boys and girls with disabilities in emergencies and armed conflict. ${ }^{61}$

45. States and non-State actors should intensify their efforts to facilitate, by every means available, the reunion of persons with disabilities with their families in accordance with their wishes. Service providers should consider the support required by some persons with disabilities in this regard. Personnel involved in these processes should be aware of the psychological impact on persons with disabilities and the potential distress caused by abandonment and violence. In addition, attention should be paid to the particular needs of unaccompanied boys and girls with disabilities, particularly those subjected to torture or trauma, and to the needs of older persons. Lastly, personnel should be aware of gender and cultural issues that could affect the process of family tracking and reunification; for example, those subjected to rape can experience shame upon reuniting with their families owing to cultural prejudices. ${ }^{62}$

46. The parties to a conflict must at all times distinguish between civilians and combatants. Attacks may only be directed against combatants. ${ }^{63}$ All parties to a conflict may only lawfully target persons with disabilities if they are actively participating in combat. ${ }^{64}$ Persons with disabilities have been identified as having taken part in hostilities as suicide bombers; ${ }^{65}$ this raises concerns about the nature and context of such participation, particularly regarding the provision of safeguards to guarantee the respect of their will and preferences without undue influence.

47. In accordance with the Convention on the Rights of Persons with Disabilities, persons with disabilities should not be forcibly held in mental health facilities or institutions. ${ }^{66}$ Any interpretation of existing provisions and standards of international humanitarian law related to medical treatment and generally accepted medical standards that allows for the detention of persons with disabilities in mental health facilities or other institutions, or for their forced treatment, should be rejected and regarded as discriminatory towards persons with disabilities, and thus contrary to the Convention. ${ }^{67}$ Furthermore,

58 See Security Council resolution 2225 (2015) and related resolutions.

$59 \mathrm{See} \mathrm{CRC} / \mathrm{C} / \mathrm{OPAC} / \mathrm{IRQ} / \mathrm{CO} / 1$, para. 31.

${ }^{60}$ ICRC, Advisory Service on International Humanitarian Law, "Penal Repression: Punishing War Crimes", January 2004, p. 1.

61 UNCHR, Working with Persons with Disabilities (see footnote 47), p. 9.

62 International Federation of Red Cross and Red Crescent Societies, Guidelines on family reunification for National Red Cross and Red Crescent Societies, 2001, p. 7.

63 The principle of distinction is now codified in articles 48, 51(2) and 52(2) of Protocol Additional to the Geneva Conventions of 12 August 1949 and relating to the Protection of Victims of International Armed Conflicts (Protocol I).

64 Protocol I to the Geneva Conventions of 12 August 1949, arts. 43, 44, 45 and related articles.

65 e-Include, "People with intellectual disabilities in armed conflict", 30 October 2012.

$66 \mathrm{See} \mathrm{CRPD} / \mathrm{C} / \mathrm{GC} / 2$, paras. 40 and 41 ; see also CRPD/C/ESP/CO/1, para. 36; CRPD/C/HUN/CO/1, para. 28; CRPD/C/AUT/CO/1, para. 31; CRPD/C/AUS/CO/1, para. 34; CRPD/C/SWE/CO/1, para. 36; CRPD/C/MEX/CO/1, para. 30; and CRPD/C/KOR/CO/1, para. 26.

67 See Geneva Convention relative to the Treatment of Prisoners of War, art. 30; see also Cathy J. Schlund-Vials and Michael Gill, eds., Disability, Human Rights and the Limits of Humanitarianism (Farnham, Surrey, Ashgate, 28 June 2014), p. 163) and Protocol additional to the Geneva Conventions of 12 August 1949 and relating to the Protection of Victims of International Armed Conflicts (Protocol I). 
States should not detain asylum seekers with disabilities beyond the scope allowed under international human rights law. ${ }^{68}$

48. All parties to a conflict have an obligation to provide prisoners of war with disabilities with accessibility and reasonable accommodation. According to the jurisprudence of the Committee on the Rights of Persons with Disabilities, all persons with disabilities who have been deprived of their liberty should have access to reasonable accommodation and appropriate measures to ensure that they can live independently and participate fully in all aspects of life within their places of detention. ${ }^{69}$ Reasonable accommodation is requested in order not to aggravate incarceration conditions for persons with disabilities. ${ }^{70}$ Moreover, places of detention should also take into account any additional requirements that may arise as detainees age.

49. The socioeconomic reintegration of ex-combatants with disabilities requires the establishment of comprehensive support systems, which should include social services to enable them to reconnect with their communities. ${ }^{71}$ Rehabilitation services should facilitate the reintegration of ex-combatants in livelihoods, and be seen as only one part of the reintegration process. Practices that focus only on the medical aspect risk isolating excombatants and generating challenges to their reintegration.

\section{Transformation through innovation}

50. Innovation is essential in making policies related to disaster risk reduction and humanitarian emergencies inclusive of and accessible to persons with disabilities. The Convention on the Rights of Persons with Disabilities promotes the concept of universal design, connected to the principle of accessibility, which should guide all policies, and, in particular, those on reconstruction, and stresses the role of information and communications technology. In addition, article 32 (d) of the Convention promotes the transfer of technologies as part of international cooperation.

51. States should "build back better", ensuring that all post-emergency and post-conflict reconstruction complies with the principles of accessibility and universal design. House reconstruction should be undertaken from this perspective, with attention paid to the specific requirements of persons with disabilities, including the provision of wheelchair access, single-level living and easy access, and orientation to community amenities. Making public transport, temporary accommodation, emergency shelters, workplaces, communications systems, schools, medical facilities, parks and government offices accessible strengthens the right of persons with disabilities to choose where and with whom they live, on an equal basis with others. It is important to include the principles of accessibility and universal design in indicators and to lay them down as design parameters and criteria for resource allocation and outcome indicators.

52. New technologies present opportunities to enhance informed decision-making in a crisis and during evacuations, as well as improving aid delivery. Mobile telephones, social media, the Internet and electronic support for crisis mapping and electronic data interchange are some of the tools that can help persons with disabilities to gain situational awareness and to overcome barriers to information and programme assistance. They may

\footnotetext{
68 Human Rights Committee, general comment No. 35 (CCPR/C/GC/35).

${ }^{69} \mathrm{CRPD} / \mathrm{C} / 11 / \mathrm{D} / 8 / 2012$, para. 9 (b)(i); see also CRPD/C/COK/CO/1, para. 28 (b); CRPD/C/CZE/CO/1, para. 28; and CRPD/C/MNG/CO/1, para. 26.

$70 \mathrm{CRPD} / \mathrm{C} / \mathrm{MNG} / \mathrm{CO} / 1$, para. 26.

71 ILO, Socio-economic reintegration of ex-combatants, 2010, pp. 90-96.
} 
also facilitate the dissemination of early warnings of disasters and evacuation ${ }^{72}$ and the delivery of goods and services, including cash transfers and transportation vouchers, among others. In order to reach the full potential of such technologies, however, adequate testing, piloting and training of service providers and persons with disabilities are required. New technology can significantly improve humanitarian intervention; if, however, the technology is not inclusive and accessible to persons with disabilities, or not affordable, it will only reproduce barriers and exclusion. Australia, Colombia, the Republic of Korea and Slovakia highlighted the relevance of new technologies in their contributions submitted to OHCHR for the preparation of the present report.

53. It is important to recall that innovation in humanitarian interventions requires more than improvements in management, programme delivery and reconstruction; it should also have a positive impact on the quality of the social outcomes attained. Quality control of successful innovations in humanitarian interventions, risk assessment and contingency planning should include, as part of the assessment criteria, accessibility, universal design, participation, accountability, non-discrimination, empowerment and compliance with international human rights standards, in particular the Convention on the Rights of Persons with Disabilities.

\section{Conclusions and recommendations}

54. The Convention on the Rights of Persons with Disabilities shifts the paradigm on disability from regarding persons with disabilities as objects of medical care and charity to recognizing them as subjects of rights. This human rights-based approach to disability demands a new understanding of international humanitarian law, refugee law and emergency frameworks as applied to persons with disabilities. States, nonState actors and humanitarian actors should reform their policies and practices in compliance with the Convention to address situations of risk and humanitarian emergency.

55. International humanitarian law and international human rights law should be viewed as complementary and mutually reinforcing with regard to the protection of the rights of persons with disabilities in situations of risk and humanitarian emergency. Standards demanding a total ban on the deprivation of liberty based on impairment and non-consensual detention in mental health facilities and other institutions, and the duty to provide reasonable accommodation to persons with disabilities deprived of their liberty, should inform the interpretation and implementation of international humanitarian law.

56. Adequate and timely delivery of accessible information is crucial in times of emergency. The use of multiple and innovative means of communication can improve accessibility and help to ensure that no constituency of persons with disabilities is excluded throughout the different stages of the emergency response, including recovery and reconstruction. States, non-State actors and other humanitarian actors should ensure the effective management and dissemination of accessible information at all stages of response.

57. Participation, accountability, non-discrimination and empowerment are fundamental principles of a human rights-based approach to disability. Ensuring these principles contributes to the enjoyment of human rights and is a proven,

72 The Danish Emergency Management Agency is developing a new, free and accessible early warning application for smartphones. 
effective way to avoid the exclusion of persons with disabilities. States and humanitarian actors should ensure active participation of and coordination and meaningful consultation with persons with disabilities and their representative organizations, including of women, men, boys and girls with disabilities of all ages and at all levels.

58. Resource allocation is a key factor in ensuring adequate responses for persons with disabilities and in building resilience in the face of future emergencies. States should mobilize adequate, timely and predictable resources to operationalize their commitment to emergency preparedness and response that are inclusive of and accessible to persons with disabilities, following a human rights-based approach to programming.

59. Evidence has shown that there is often a lack of capacity in field operations supporting persons with disabilities in situations of risk and humanitarian emergency. States, non-State actors and humanitarian actors should build capacity of stakeholders, both military and civilian, peacekeeping personnel, and other field workers intervening in emergency situations regarding the rights of persons with disabilities.

60. Reconstruction and rebuilding offer a unique opportunity to "build back better". When adopting a human rights-based approach, States and humanitarian actors should ensure accessibility through universal design in programming, and in all post-emergency reconstruction and rebuilding, particularly during planning and reconstruction of infrastructure and public facilities. International cooperation should be implemented in accordance with the standards established in the Convention on the Rights of Persons with Disabilities. Universal design and accessibility and nondiscrimination should be integral outcome indicators, design parameters and resource allocation criteria for quality reconstruction and rebuilding.

61. Prevention of primary impairments should be part of health strategies or other mainstream strategies for the prevention of risks, without any negative impact on the allocation of resources to disability-related strategies. Humanitarian actors should avoid including in their disability-related strategies issues concerning the prevention of primary impairments.

62. Current Security Council frameworks collect information on civilians, children and women in conflict. Mainstreaming persons with disabilities into these efforts and mechanisms would facilitate data collection on their situation. States should promote the inclusion of persons with disabilities in existing United Nations frameworks that address conflict and emergency situations, and provide high-level support and develop internationally agreed standards and guidelines on the inclusion of persons with disabilities in humanitarian action. 